University of Nebraska - Lincoln

DigitalCommons@University of Nebraska - Lincoln

4-2008

\title{
Synoptic Monitoring of Gross Primary Productivity of Maize Using Landsat Data
}

Anatoly A. Gitelson

University of Nebraska at Lincoln, agitelson2@unl.edu

Andrés Viña

Michigan State University

Jeffrey G. Masek

NASA Goddard Space Flight Center, Greenbelt, MD

Shashi Verma

University of Nebraska - Lincoln, sverma1@unl.edu

Andrew E. Suyker

University of Nebraska - Lincoln, asuyker1@unl.edu

Follow this and additional works at: https://digitalcommons.unl.edu/natrespapers

Part of the Natural Resources and Conservation Commons

Gitelson, Anatoly A.; Viña, Andrés; Masek, Jeffrey G.; Verma, Shashi; and Suyker, Andrew E., "Synoptic Monitoring of Gross Primary Productivity of Maize Using Landsat Data" (2008). Papers in Natural Resources. 223.

https://digitalcommons.unl.edu/natrespapers/223

This Article is brought to you for free and open access by the Natural Resources, School of at DigitalCommons@University of Nebraska - Lincoln. It has been accepted for inclusion in Papers in Natural Resources by an authorized administrator of DigitalCommons@University of Nebraska - Lincoln. 


\title{
Synoptic Monitoring of Gross Primary Productivity of Maize Using Landsat Data
}

\author{
Anatoly A. Gitelson, Andrés Viña, Jeffrey G. Masek, Shashi B. Verma, and Andrew E. Suyker
}

\begin{abstract}
There is a growing interest in monitoring the gross primary productivity (GPP) of crops due mostly to their carbon sequestration potential. Both within- and between-field variability are important components of crop GPP monitoring, particularly for the estimation of carbon budgets. In this letter, we present a new technique for daytime GPP estimation in maize based on the close and consistent relationship between GPP and crop chlorophyll content, and entirely on remotely sensed data. A recently proposed chlorophyll index (CI), which involves green and near-infrared spectral bands, was used to retrieve daytime GPP from Landsat Enhanced Thematic Mapper Plus $($ ETM+) data. Because of its high spatial resolution (i.e., $30 \times$ $30 \mathrm{~m} /$ pixel), this satellite system is particularly appropriate for detecting not only between- but also within-field GPP variability during the growing season. The $\mathrm{CI}$ obtained using atmospherically corrected Landsat ETM+ data was found to be linearly related with daytime maize GPP: root mean squared error of less than $1.58 \mathrm{gC} \cdot \mathrm{m}^{-2} \cdot \mathrm{d}^{-1}$ in a $\mathrm{GPP}$ range of 1.88 to $23.1 \mathrm{gC} \cdot \mathrm{m}^{-2} \cdot \mathrm{d}^{-1}$; therefore, it constitutes an accurate surrogate measure for GPP estimation. For comparison purposes, other vegetation indices were also tested. These results open new possibilities for analyzing the spatiotemporal variation of the GPP of crops using the extensive archive of Landsat imagery acquired since the early 1980s.
\end{abstract}

Index Terms-Optical imaging, remote sensing, vegetation mapping.

\section{INTRODUCTION}

C ROPS are the most pervasive anthropogenic biome worldwide, playing an important role in the global cycles of carbon, water, and nutrients. The potential of crops to sequester carbon has received substantial scientific attention in the last few years (e.g., [1]). In particular, the maize/soybeanbased cropping systems, which dominate the north-central U.S. agricultural region, are considered to have a significant but still underutilized sequestration potential [2]. Hybrids and field management practices have changed over the last three decades, increasing crop yields, decreasing tillage, and increasing residue inputs to the soil, among others [3]. These changes have impacts on the amount of atmospheric carbon

Manuscript received July 20, 2007; revised August 29, 2007. This work was supported by in part by the NASA Land Cover and Land Use Change Program under Grant NNG06GG17G, in part by the U.S. Department of Energy (DoE) EPSCoR program under Grant DE-FG-02-00ER45827 and the DoE Office of Science (BER) under Grant DE-FG02-03ER63639, and in part by the Hatch Act.

A. A. Gitelson, S. B. Verma, and A. E. Suyker are with the School of Natural Resources, University of Nebraska-Lincoln, Lincoln, NE 68588 USA.

A. Viña is with the Center for Systems Integration and Sustainability, Department of Fisheries and Wildlife, Michigan State University, East Lansing, MI 48824 USA.

J. G. Masek is with the Biospheric Sciences Branch, NASA Goddard Space Flight Center, Greenbelt, MD 20771 USA

Digital Object Identifier 10.1109/LGRS.2008.915598 fixed through photosynthesis, as well as on the release of carbon due to organic matter decomposition.

Field studies have used eddy covariance techniques to provide information on the seasonal and interannual dynamics of carbon fluxes in crops (e.g., [4] and [5]). These techniques provide an integrated measurement of carbon fluxes over spatially-variable footprints; therefore, up-scaling beyond the footprint is crucial for regional carbon budget assessments. Since vegetation productivity is directly related to the interaction of solar radiation with the plant canopy, remote sensing techniques have been increasingly used for such up-scaling. Procedures developed, so far, can be grouped into two broad categories according to the way they model the absorption of solar radiation and its conversion into dry matter [6]: canopy photosynthesis models (CPMs) and production efficiency models (PEMs). While CPM computes the amount of leaves (i.e., leaf area index) used to absorb solar radiation, PEM directly computes the absorbed solar radiation based on the original logic of Monteith [7], which suggests that the gross primary productivity (GPP) of crops is linearly related to the amount of absorbed photosynthetically active radiation

$$
\mathrm{GPP} \propto \varepsilon \times \Sigma(f \mathrm{APAR} \times \mathrm{PAR})
$$

where PAR is the incident photosynthetically active radiation, $f$ APAR is the fraction of PAR absorbed by the crop canopy, their product integrated over a time period, and $\varepsilon$ is light use efficiency (LUE).

Most PEM are based on the assumption of a close linear relationship between the $f$ APAR and the normalized difference vegetation index (NDVI), as well as on a constant, though biome-specific, LUE [6]. Nevertheless, it has been shown that these assumptions do not hold in many circumstances. On the one hand, although LUE is a relatively conservative value among plant formations of the same metabolic type [6], its variability is species-specific rather than biome-specific [8], it changes with phenological stage [5], [9], and it depends on environmental stress factors (e.g., [10]). Many models for the remote estimation of GPP use lookup tables of maximum LUE for a given vegetation type and then adjust those values downward on the basis of environmental stress factors (e.g., [6] and [10]), but they use coarse spatial resolution meteorological variables, which also result in significant GPP estimation errors (e.g., [11] and [12]). On the other hand, a significant decrease in the sensitivity of NDVI to $f$ APAR is observed when $f$ APAR exceeds 0.7 [13]-[15]. Therefore, the uncertainty of crop GPP estimation using Monteith's logic might be considerable, due to 
the nonlinearity of the NDVI/ $f$ APAR relationship, and the lack of knowledge about factors influencing LUE.

Perhaps, a more direct approach is to devise models for GPP estimation based entirely on remotely sensed data [e.g., vegetation indices (VIs)] without depending on an estimation of LUE, therefore having a continuous output at the spatial resolution of the satellite data. However, short term (minutes to hours) variations in GPP due to short-term environmental stresses (e.g., temperature, humidity, soil moisture) cannot be estimated from VIs alone, since these short-term stresses do not affect crop greenness (i.e., canopy chlorophyll content). However, the GPP variability integrated over longer time periods (e.g., days), can be characterized by VIs obtained from data acquired by operational satellites. Strong correlations between $\mathrm{CO}_{2}$ flux and VIs such as NDVI [16]-[18] and the enhanced VI (EVI) [19], [20] have been observed for different ecosystems when the flux data were averaged over one or two weeks. These strong correlations depend on the close relationship between GPP and chlorophyll (Chl) content [21]-[23], because the energy absorbed by the canopy can only be transferred to the dark reaction of the photosynthesis by the Chl. Therefore, metrics that estimate the Chl content (e.g., VIs) constitute surrogates of the amount of energy that can be transferred to the dark reaction of the photosynthesis. Following this logic, it was shown that the product of $\mathrm{Chl}$ and incoming photosynthetically active radiation (PAR) accounted for more than $98 \%$ of GPP variation in both maize and soybeans in a wide range of PAR variation [9]. This relationship (i.e., GPP versus $\mathrm{Chl} \times$ PAR) was nonspecies specific, consistent and repeatable under rainfed and irrigated conditions [9]. Therefore, for an operational remote estimation of GPP in crops, an accurate remote estimation of Chl is required.

A recently developed conceptual model with a solid physical background has been widely used for the nondestructive retrieval of various pigments in different media such as leaves, crop canopies, fruits and turbid productive waters [24]-[26]. Chlorophyll indices (CIs) that employ bands in the near infrared and either green or red-edge spectral regions are a special case of this conceptual model, and have been linearly related with crop Chl content [24], as well as successfully used for maize and soybean midday GPP estimation [9]. However, this approach has only been tested using close range sensing techniques. In this letter, we examined the performance of the approach for the remote estimation of daily integrated GPP of irrigated and rainfed maize using data acquired by the Landsat Enhanced Thematic Mapper Plus (ETM+) satellite system. Because of its high spatial resolution (i.e., $30 \times 30 \mathrm{~m} /$ pixel), this satellite system is particularly appropriate for detecting not only between but also within field GPP variability during a growing season. For comparison purposes, other indices that also respond to canopy $\mathrm{Chl}$ content, and that have been also successfully used for GPP retrieval, were also tested.

\section{METHODS}

This study used three sites located at the University of Nebraska Agricultural Research and Development Center near Mead, Nebraska. These sites are large production fields (49 to
$65 \mathrm{ha}$ ) and provide sufficient upwind fetch of uniform cover required for adequately measuring mass and energy fluxes using tower eddy covariance systems. Two sites $\left(1: 41^{\circ} 09^{\prime} 54.2^{\prime} \mathrm{N}\right.$, $96^{\circ} 28^{\prime} 35.9^{\prime \prime} \mathrm{W} ; 2: 41^{\circ} 09^{\prime} 53.5^{\prime \prime} \mathrm{N}, 96^{\circ} 28^{\prime} 12.3^{\prime \prime} \mathrm{W}$ ) are equipped with center-pivot irrigation systems while the third site (3: $41^{\circ} 10^{\prime} 46.8^{\prime \prime} \mathrm{N}, 96^{\circ} 26^{\prime} 22.7^{\prime \prime} \mathrm{W}$ ) relies on rainfall. Soils of the three study sites are composed of deep silty clay loam. In 2001, all three sites were under maize, while in 2002 only one site (site 1) was under maize.

To have sufficient upwind fetch (in all directions), eddy covariance sensors were mounted at $3 \mathrm{~m}$ above the ground while the canopy was shorter than $1 \mathrm{~m}$, and later moved to a height of $6.2 \mathrm{~m}$ until harvest (details are given elsewhere: [5]). Each of these fields represented approximately $90 \%-95 \%$ of the flux tower footprint during daytime and 70\%-90\% during nighttime. Daytime net ecosystem exchange (NEE) values were computed by integrating the $\mathrm{CO}_{2}$ fluxes collected by the eddy covariance tower from 8:30 and 18:30, so that the sun elevation was $5^{\circ}$ or more in all dates. Daytime ecosystem respiration was calculated from the nighttime $\mathrm{CO}_{2}$ exchange/temperature $\mathrm{Q}_{10}$ relationship as used in [5]. GPP (in grams of carbon per square meter per day, $\mathrm{gC} \cdot \mathrm{m}^{-2} \cdot \mathrm{d}$ ) was then obtained by subtracting daytime respiration from NEE. This approach has been widely used in the context of tower flux measurements and is considered to provide reasonable estimates at the landscape level [4], [5].

Four Landsat-7 ETM+ images (WRS-2 path 28, row 31) acquired throughout the 2001 growing season (June 10, August 13 and 29, and September 30) and one image acquired in July 15, 2002 were used in this letter. These images were first coregistered manually by picking ground control points using the environment for visualizing images (ENVI) processing package, and then resampled to a common grid $(30 \times$ $30 \mathrm{~m} / \mathrm{pixel})$. The images were atmospherically corrected to the top-of-canopy reflectance using the Landsat Ecosystem Disturbance Adaptive Processing System (LEDAPS) at the NASA Goddard Space Flight Center [27]. The atmospheric correction procedure corrects for gaseous absorption, Rayleigh scattering, and Mie (aerosol) scattering using the Moderate Resolution Imaging Spectroradiometer (MODIS)/6S radiative transfer model [28]. Ozone concentrations were derived from Total Ozone Mapping Spectrometer (TOMS) data aboard the Nimbus-7, Meteor-3, and Earth Probe platforms. Column water vapor is taken from "National Oceanic and Atmospheric Administration National Centers for Environmental Prediction's reanalysis data" available at a resolution of $2.5^{\circ} \times 2.5^{\circ}$. Aerosol optical thickness was derived for each image using the dark, dense vegetation approach [29]. Based on the physical correlation between chlorophyll absorption and bound water absorption, this method postulates a linear relation between shortwave-infrared $(2.2 \mu \mathrm{m})$ surface reflectance (nearly unaffected by the atmosphere) and surface reflectance in the visible bands. By using the relation to calculate surface reflectance for the visible bands, and comparing the result to the top-of-atmosphere reflectance, the aerosol optical depth was estimated. LEDAPS surface reflectance products have been compared to in situ data from the Aerosol Robotic Network (AERONET) and to daily, 500-m resolution surface reflectance 

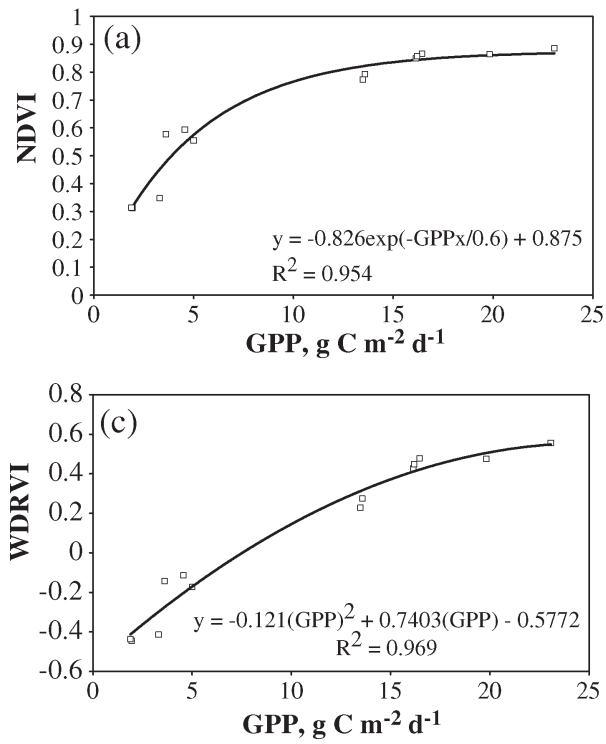

Fig. 1. Relationships between four VIs and daytime GPP.

products from the MODIS sensor onboard the NASA Terra spacecraft [27]. The uncertainties associated with the calculated reflectance values are within the uncertainty of the MODIS surface reflectance product (the greater of $0.5 \%$ absolute reflectance or $5 \%$ of the recorded reflectance value) for normal aerosol loadings $\left(\tau_{550 \mathrm{~nm}}<0.5\right)$.

Green $\mathrm{CI}\left(\mathrm{CI}_{\text {green }}\right)$ was calculated as

$$
\mathrm{CI}_{\text {green }}=\left(\rho_{\text {NIR }} / \rho_{\text {green }}\right)-1
$$

where $\rho_{\text {NIR }}$ and $\rho_{\text {green }}$ are surface reflectances in the nearinfrared (NIR) and green bands of the Landsat ETM+ system, respectively. For comparison purposes, three other VIs were calculated to assess their accuracy for GPP estimation

$$
\begin{aligned}
\mathrm{NDVI} & =\left(\rho_{\mathrm{NIR}}-\rho_{\text {red }}\right) /\left(\rho_{\text {NIR }}+\rho_{\text {red }}\right) \\
\mathrm{EVI} & =2.5\left(\rho_{\mathrm{NIR}}-\rho_{\text {red }}\right) /\left(1+\rho_{\mathrm{NIR}}+6 \rho_{\text {red }}-7 \rho_{\text {blue }}\right) \\
\mathrm{WDRVI} & =\left(\alpha \rho_{\mathrm{NIR}}-\rho_{\text {red }}\right) /\left(\alpha \rho_{\mathrm{NIR}}+\rho_{\text {red }}\right)
\end{aligned}
$$

where WDRVI is wide dynamic range VI [30] developed to increase the sensitivity to changes in vegetation with moderate-tohigh densities, where NDVI saturates. WDRVI was calculated with an $\alpha=0.1$, found to be optimal for surface reflectance data [30]. With the exception of the WDRVI, all of these indices have been reported to be linearly related with time-integrated GPP in different ecosystems (e.g., [9], [16]-[19]).

Since the study sites represented approximately $90 \%-95 \%$ of the daytime flux tower footprints [5], site VI values were obtained by averaging all the per-pixel VI values within the fields for each date of image acquisition. Although this spatial averaging was not necessary due to field homogeneity [9], it was performed to calibrate the models using the footprint of the tower-based GPP measurements.

GPP values used were the daily integrals of the instantaneous GPP for the day of image acquisition; however, they do reflect previous environmental conditions. The same is the case for the VI values that are governed by crop greenness (i.e., Chl content which reflects previous environmental and management
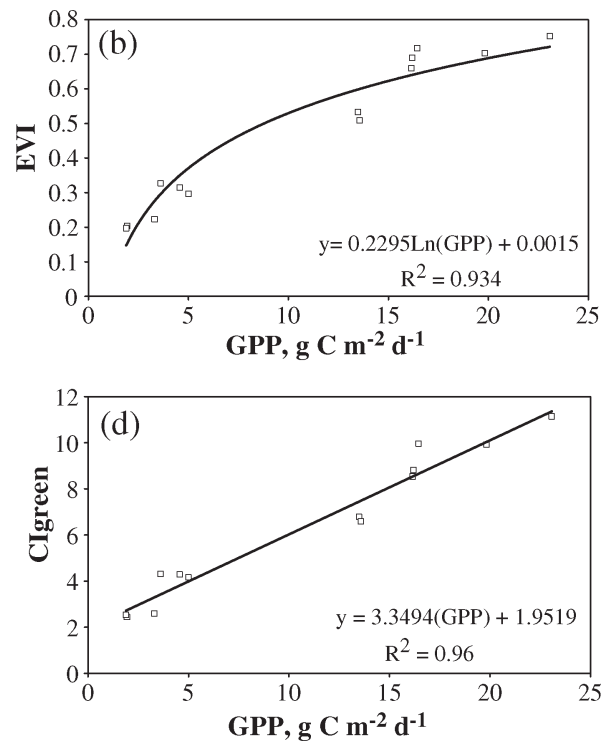

conditions) and do not depend on the incoming PAR of the image acquisition date. Thus, we performed the comparison of daily integrated GPP directly with the VIs obtained from cloud-free and atmospherically corrected imagery (as opposed to the product of VI and incoming PAR used at close range [9], which allowed to collect reflectance data even under cloudy conditions).

Site VI values were regressed against the average daytime GPP values obtained by the eddy covariance technique for the same days of image acquisitions. Best-fit-functions and parameters were obtained for each VI versus GPP relation tested.

To compare the sensitivity of each of the above VIs to changes in GPP, the noise equivalent GPP (NE $\Delta$ GPP) was calculated as

$$
\mathrm{NE} \Delta \mathrm{GPP}=\operatorname{rmse}(\mathrm{VI} \text { versus GPP }) /[\mathrm{d}(\mathrm{VI}) / \mathrm{d}(\mathrm{GPP})]
$$

where rmse is the root mean squared error of the relationship VI versus GPP, and $d(\mathrm{VI}) / \mathrm{d}(\mathrm{GPP})$ is the first derivative of VI with respect to GPP. Thus, NE $\triangle$ GPP brings the rmse value adjusted for sensitivity of the VI to GPP. Defined in this way, the noise equivalent allows the direct comparison among different indices, with different scales and dynamic ranges [15].

\section{RESUlts AND Discussion}

The daytime GPP varied widely, ranging from $1.88 \mathrm{gC}$. $\mathrm{m}^{-2} \cdot \mathrm{d}^{-1}$ in June 2001 to $23.1 \mathrm{gC} \cdot \mathrm{m}^{-2} \cdot \mathrm{d}^{-1}$ in July 2002, which requires a wide dynamic range of the remote sensing technique for an accurate GPP assessment. The five Landsat-7 ETM+ images used in this letter provided observations for all maize physiological stages: green-up (June and July), reproduction (beginning of August) and senescence (end of August to late September).

The VI versus GPP relationship was calculated using linear and nonlinear regressions (Fig. 1). The NDVI versus GPP relationship was asymptotic, with a significant decrease in the slope as GPP exceeds $10 \mathrm{gC} \cdot \mathrm{m}^{-2} \cdot \mathrm{d}^{-1}$ [Fig. 1(a)]. Thus, 


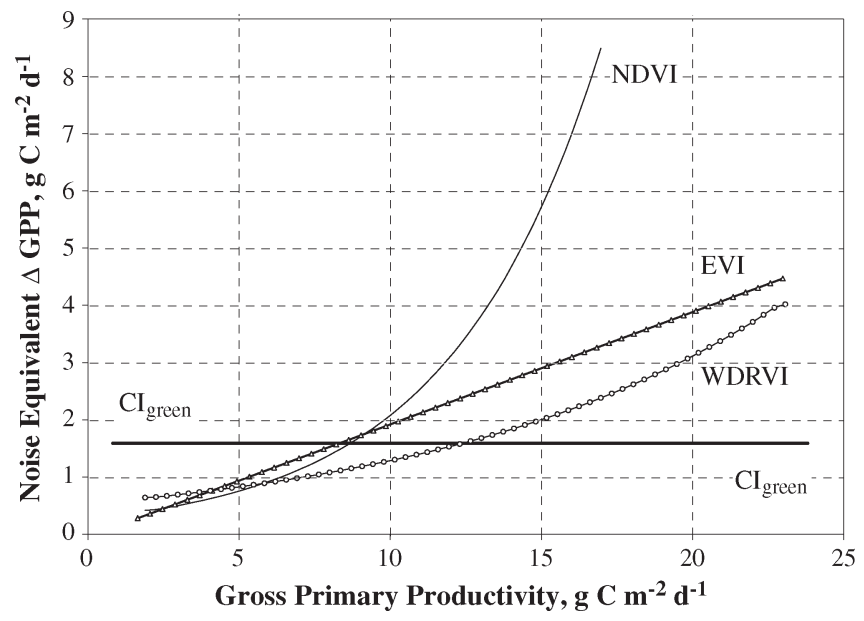

Fig. 2. Noise equivalent of GPP estimation by four VIs plotted versus daytime GPP.

NDVI exhibits limitations in GPP estimation at moderate to high vegetation densities, similar to what was found for the relationship between NDVI and the fraction of incoming PAR absorbed by photosynthetically active vegetation [15]. It prevents an accurate estimation of GPP $>10 \mathrm{gC} \cdot \mathrm{m}^{-2} \cdot \mathrm{d}^{-1}$, which corresponds to more than two months of the growing season in irrigated and rainfed maize [5]. Both EVI and WDRVI also exhibited asymptotic relationships with GPP with decrease in sensitivity as GPP exceeded $15 \mathrm{gC} \cdot \mathrm{m}^{-2} \cdot \mathrm{d}^{-1}$. However, the sensitivity of these indices to moderate to high GPP was higher than that of NDVI [Fig. 1(b) and (c)]. The relationship $\mathrm{CI}_{\text {green }}$ versus GPP was linear with a coefficient of determination of 0.96 , and an rmse of GPP estimation of less than $1.58 \mathrm{gC}$. $\mathrm{m}^{-2} \cdot \mathrm{d}^{-1}$ in the range of GPP from 1.88 to $23.1 \mathrm{gC} \cdot \mathrm{m}^{-2} \cdot \mathrm{d}^{-1}$ [Fig. 1(d)].

The noise equivalent of GPP estimation by each VI is shown in Fig. 2. NDVI and EVI had minimal NE $\Delta$ GPP for $\mathrm{GPP}<5 \mathrm{gC} \cdot \mathrm{m}^{-2} \cdot \mathrm{d}^{-1}$. With GPP $>8 \mathrm{gC} \cdot \mathrm{m}^{-2} \cdot \mathrm{d}^{-1}$, the NE $\triangle$ GPP of NDVI increased exponentially, reaching $28 \mathrm{gC} \cdot \mathrm{m}^{-2} \cdot \mathrm{d}^{-1}$ for $\mathrm{GPP}=23 \mathrm{gC} \cdot \mathrm{m}^{-2} \cdot \mathrm{d}^{-1}$ (not shown in Fig. 2). In the range of GPP from 5 to $12 \mathrm{gC} \cdot \mathrm{m}^{-2} \cdot \mathrm{d}^{-1}$, WDRVI had the lowest noise equivalent. With increase in GPP beyond $10 \mathrm{gC} \cdot \mathrm{m}^{-2} \cdot \mathrm{d}^{-1}$, NE $\triangle$ GPP of both EVI and WDRVI also increased but at lower rates than that of NDVI. However, NE $\triangle$ GPP of EVI and WDRVI became much higher (2.5-fold for WDRVI and 3-fold for EVI) than that of $\mathrm{CI}_{\text {green }}$ at maximal GPP values.

The $\mathrm{CI}_{\text {green }}$ was the most accurate index for GPP beyond $12 \mathrm{gC} \cdot \mathrm{m}^{-2} \cdot \mathrm{d}^{-1}$ and it appeared to be the most suitable index for the estimation of GPP using Landsat ETM+ data. Since the relationship is linear, it is straightforward to invert it between $\mathrm{CI}_{\text {green }}$ and GPP to obtain a synoptic measure of GPP. The differential sensitivity of the $\mathrm{CI}_{\text {green }}$ and other VIs to GPP could be combined optimizing the monitoring of GPP using a single, blended index (details are given in [31]).

These results are promising; however, there are several limitations of the approach. First, variations in GPP due to short term environmental stresses and irradiation conditions cannot be estimated by $\mathrm{CI}_{\text {green }}$ as well as by other VIs, if these stresses do not affect crop Chl. The inclusion of other remote sensing products, such as the land surface temperature and indices for the estimation of leaf water content (e.g., [32] and [33]) may result in more robust models of carbon balance based entirely on remote sensing data. Second, $\mathrm{CI}_{\text {green }}$, as well as other VIs, are species specific (i.e., the coefficients of the VI versus GPP relations depend on the species) [9], [24]. Thus, the $\mathrm{CI}_{\text {green }}$ calculated with sensor systems with coarse spatial resolutions (e.g., MODIS $500 \mathrm{~m} / \mathrm{pixel}$ ) becomes less accurate for crop GPP estimation, due to the increase in within pixel heterogeneity, as more species with different types of canopy architecture and leaf structure might be included within a single pixel. Thus, at coarse spatial resolutions, the use of a different spectral region would be recommended. For instance, it was found that the linear relationship between $\mathrm{Chl}$ and a red edge chlorophyll index is not species specific [24]. Thus, this index can be used for GPP retrieval when a pixel includes different species, but only using sensor systems that collect reflectance data in the red-edge spectral region (e.g., MERIS, HYPERION). Third, the effects of soil color variability on GPP retrieval are not completely understood. We are presently evaluating these effects on the accuracy of maize GPP retrieval, although they are minimized once the maize canopy cover exceeds $60 \%$ (i.e., day of the year beyond 170). Finally, the use of satellite data in general and Landsat ETM+ data in particular, for the remote estimation of annual crop GPP and its multiannual variation, is limited by the availability of cloud-free data, requiring the use of temporal interpolations (e.g., maximum value compositing). An evaluation of the archive of cloud-free Landsat ETM+ imagery of the corn-belt region of the U.S. (between 2001 and 2006) suggests that an average of eight image acquisitions are available to be used for each growing season. This Landsat ETM+ imagery can also be complemented by Landsat TM imagery, extending the temporal resolution of the image time series. Therefore, with adequate data assimilation techniques that allow to incorporate incomplete and/or noisy measurements from remote sensing platforms (e.g., [34] and [35]), a suitable time-series of imagery can be obtained for monitoring both the spatial (within and between fields) and temporal (within and between growing seasons) variability of GPP, using Landsat data.

\section{CONCLUSION}

We explore the potential of models based entirely on remotely sensed data for the remote estimation of GPP. Here, we have shown that the $\mathrm{CI}_{\text {green }}$ index is linearly related with GPP, therefore, when applied to atmospherically corrected Landsat ETM+ data, it appears to be the best one among the four tested, to obtain accurate synoptic estimates of the daytime maize GPP for a wide range of vegetation biomass (including moderate to high values), where other VIs lose sensitivity. The implications of these findings are far-reaching, since the $\mathrm{CI}_{\text {green }}$ opens a new possibility for an accurate remote GPP estimation of crops using the extensive archive of Landsat imagery acquired since the early 1980s. With this index, it could be possible to obtain global synoptic estimates of GPP in crops at the moderate spatial resolution of Landsat TM and ETM+. Other satellite sensor systems that contain the red and the NIR bands only (e.g., MODIS- $250 \mathrm{~m} / \mathrm{pixel}$ and the Advanced Very High 
Resolution Radiometer), can also be utilized to obtain synoptic estimates of GPP, if the WDRVI is used instead.

\section{ACKNOWLEDGMENT}

The authors would like to thank the support and the use of facilities and equipment provided by the Center for Advanced Land Management Information Technologies and the Carbon Sequestration program, University of Nebraska-Lincoln. The authors would also like to thank Dr. F. Jacob and five anonymous reviewers for their very valuable and constructive criticism, comments, and suggestions to the manuscript. This is a contribution of the University of Nebraska Agricultural Research Division, Lincoln, NE.

\section{REFERENCES}

[1] L. M. Vleeshouwers and A. Verhagen, "Carbon emission and sequestration by agricultural land use: A model study for Europe," Global Change Biol., vol. 8, no. 6, pp. 519-530, Jun. 2002.

[2] C. J. Bernacchi, S. E. Hollinger, and T. Meyers, "The conversion of the corn/soybean ecosystem to no-till agriculture may result in a carbon sink," Global Change Biol., vol. 11, no. 11, pp. 1867-1872, Nov. 2005.

[3] J. E. Specht, D. J. Hume, and S. V. Kumudini, "Soybean yield potential-A genetic and physiological perspective," Crop Sci., vol. 39, no. 6, pp. 1560-1570, Nov. 1999.

[4] D. D. Baldocchi, "A comparative study of mass and energy exchange rates over a closed $\mathrm{C} 3$ (wheat) and an open $\mathrm{C} 4$ (corn) crop: II $\mathrm{CO}_{2}$ exchange and water use efficiency," Agric. For. Meteorol., vol. 67, no. 3/4, pp. 291321, Jan. 1994.

[5] A. E. Suyker, S. B. Verma, G. G. Burba, and T. J. Arkebauer, "Gross primary production and ecosystem respiration of irrigated maize and irrigated soybean during a growing season," Agric. For. Meteorol., vol. 131, no. 3/4, pp. 180-190, Aug. 2005.

[6] A. Ruimy, L. Kergoat, and A. Bondeau, "Comparing global models of terrestrial net primary productivity (NPP): Analysis of differences in light absorption and light-use efficiency," Global Change Biol., vol. 5, no. 1, pp. 56-64, Apr. 1999.

[7] J. L. Monteith, "Solar radiation and productivity in tropical ecosystems," J. Appl. Ecol., vol. 9, no. 3, pp. 744-766, Dec. 1972.

[8] D. E. Ahl, S. T. Gower, D. S. Mackay, S. N. Burrows, J. M. Norman, and G. R. Diak, "Heterogeneity of light use efficiency in a northern Wisconsin forest: Implications for modeling net primary production with remote sensing," Remote Sens. Environ., vol. 93, no. 1/2, pp. 168-178, Oct. 2004.

[9] A. A. Gitelson, A. Viña, S. B. Verma, D. C. Rundquist, T. J. Arkebauer, G. Keydan, B. Leavitt, V. Ciganda, G. G. Burba, and A. E. Suyker, "Relationship between gross primary production and chlorophyll content in crops: Implications for the synoptic monitoring of vegetation productivity," J. Geophys. Res., vol. 111, D08 S11, 2006. DOI:10.1029/2005JD006017.

[10] S. W. Running, R. R. Nemani, F. A. Heinsch, M. S. Zhao, M. Reeves, and H. Hashimoto, "A continuous satellite-derived measure of global terrestrial primary production," Bioscience, vol. 54, no. 6, pp. 547-560, Jun. 2004.

[11] D. P. Turner, W. D. Ritts, W. B. Cohen, T. K. Maeirsperger, S. T. Gower, A. A. Kirschbaum, S. W. Running, M. S. Zhao, S. C. Wofsy, A. L. Dunn, B. E. Law, J. L. Campbell, W. C. Oechel, H. J. Kwon, T. P. Meyers, E. E. Small, S. A. Kurc, and J. A. Gamon, "Site-level evaluation of satellite-based global terrestrial gross primary production and net primary production monitoring," Global Change Biol., vol. 11, no. 4, pp. 666-684, Apr. 2005. DOI:10.1111/j.1365-2486.2005.00936.x.

[12] M. Zhao, F. A. Heinsch, R. R. Nemani, and S. W. Running, "Improvements of the MODIS terrestrial gross and net primary production global data set," Remote Sens. Environ., vol. 95, no. 2, pp. 164-176, Mar. 2005.

[13] G. Asrar, M. Fuchs, E. T. Kanemasu, and J. H. Hatfield, "Estimating absorbed photosynthetic radiation and leaf area index from spectral reflectance in wheat," Agron. J., vol. 76, pp. 300-306, 1984.

[14] S. N. Goward and K. F. Huemmrich, "Vegetation canopy PAR absorptance and the normalized difference vegetation index: An assessment using the SAIL model," Remote Sens. Environ., vol. 39, no. 2, pp. 119-140, Feb. 1992

[15] A. Viña and A. A. Gitelson, "New developments in the remote estimation of the fraction of absorbed photosynthetically active radia- tion in crops," Geophys. Res. Lett., vol. 32, no. 17, p. L17 403, 2005. DOI: $10.1029 / 2005$ GL023647.

[16] S. N. Goward, C. J. Tucker, and D. G. Dye, "North American vegetation patterns observed with the NOAA-7 Advanced Very High Resolution Radiometer," Vegetatio, vol. 64, pp. 3-14, 1985.

[17] E. O. Box, B. N. Holben, and V. Kalb, "Accuracy of the AVHRR vegetation index as a predictor of biomass, primary productivity and net $\mathrm{CO}_{2}$ flux," Vegetatio, vol. 80, pp. 71-89, 1989.

[18] D. A. Sims, H. Luo, S. Hastings, W. C. Oechel, A. F. Rahman, and J. A. Gamon, "Parallel adjustments in vegetation greenness and ecosystem $\mathrm{CO}_{2}$ exchange in response to drought in a southern California chaparral ecosystem," Remote Sens. Environ., vol. 103, no. 3, pp. 289-303, Aug. 2006.

[19] D. A. Sims, A. F. Rahman, V. D. Cordova, B. Z. El Masri, D. D. Baldocchi, L. B. Flanagan, A. H. Goldstein, D. Y. Hollinger, L. Misson, R. K. Monson, W. C. Oechel, H. P. Schmid, S. C. Wofsy, and L. Xu, "On the use of MODIS EVI to assess gross primary productivity of North American ecosystems," J. Geophys. Res., vol. 111, no. G4, G04 015, 2006. DOI:10.1029/2006JG000162.

[20] A. R. Huete, H. Q. Liu, K. Batchily, and W. van Leeuwen, "A comparison of vegetation indices global set of TM images for EOS-MODIS," Remote Sens. Environ., vol. 59, no. 3, pp. 440-451, Mar. 1997.

[21] H. Leith and R. H. Whittaker, Eds., "Primary productivity of the biosphere," in Ecological Studies, vol. 14. New York:Springer-Verlag, 1975, p. 339.

[22] C. Foyer, R. Leegood, and D. Walker, "What limits photosynthesis?" Nature, vol. 298, p. 326, 1982

[23] T. P. Dawson, P. R. J. North, S. E. Plummer, and P. J. Curran, "Forest ecosystem chlorophyll content: Implications for remotely sensed estimates of net primary productivity," Int. J. Remote Sens., vol. 24, no. 3 , pp. 611-617, Feb. 2003.

[24] A. A. Gitelson, A. Viña, D. C. Rundquist, V. Ciganda, and T. J. Arkebauer, "Remote estimation of canopy chlorophyll content in crops," Geophys. Res. Lett., vol. 32, L08 403, 2005. DOI:10.1029/2005GL022688.

[25] A. A. Gitelson, G. P. Keydan, and M. N. Merzlyak, "Three-band model for noninvasive estimation of chlorophyll, carotenoids, and anthocyanin contents in higher plant leaves," Geophys. Res. Lett., vol. 33, p. L11 402, 2006. DOI:10.1029/2006GL026457.

[26] G. Dall'Olmo and A. A. Gitelson, "Effect of bio-optical parameter variability and uncertainties in reflectance measurements on the remote estimation of chlorophyll-a concentration in turbid productive waters: Modeling results," Appl. Opt., vol. 45, no. 15, pp. 3577-3592, 2006

[27] J. G. Masek, E. F. Vermote, N. Saleous, R. Wolfe, F. G. Hall, F. Huemmrich, F. Gao, J. Kutler, and T. K. Lim, "A Landsat surface reflectance dataset for North America, 1990-2000," IEEE Geosci. Remote Sens. Lett., vol. 3, no. 1, pp. 68-72, Jan. 2006.

[28] E. F. Vermote, N. El Saleous, C. O. Justice, Y. J. Kaufman, J. L. Privette, L. Remer, J. C. Roger, and D. Tanré, "Atmospheric correction of visible to middle-infrared EOS-MODIS data over land surfaces: Background, operational algorithm, and validation," J. Geophys. Res., vol. 102, no. D14, pp. $17131-17141,1997$

[29] Y. J. Kaufman, A. E. Wald, L. A. Remer, B.-C. Gao, R.-R. Li, and L. Flynn, "The MODIS 2.1- $\mu \mathrm{m}$ channel-Correlation with visible reflectance for use in remote sensing of aerosol," IEEE Trans. Geosci. Remote Sens., vol. 35, no. 5, pp. 1286-1296, Sep. 1997.

[30] A. A. Gitelson, "Wide dynamic range vegetation index for remote quantification of biophysical characteristics of vegetation," J. Plant Phys., vol. 161, no. 2, pp. 165-173, Feb. 2004.

[31] A. A. Gitelson and Y. Kaufman, "MODIS NDVI optimization to fit the AVHRR data series-Spectral considerations," Remote Sens. Environ., vol. 66, no. 3, pp. 343-350, Dec. 1998.

[32] B. Gao, "NDWI-A normalized difference water index for remote sensing of vegetation liquid water from space," Remote Sens. Environ., vol. 58, no. 3, pp. 257-266, Dec. 1996.

[33] E. R. Hunt, Jr. and B. N. Rock, "Detection of changes in leaf water content using near- and middle-infrared reflectances," Remote Sens. Environ., vol. 30 , no. 1 , pp. $43-54$, Oct. 1989.

[34] P. Cayrol, A. Chehbouni, L. Kergoat, G. Dedieu, P. Mordelet, and Y. Nouvellon, "Grassland modeling and monitoring with SPOT-4 VEGETATION instrument during the 1997-1999 SALSA experiment," Agric. For. Meteorol., vol. 105, no. 1-3, pp. 91-115, Nov. 2000.

[35] R. Hadria, B. Duchemin, A. Lahrouni, S. Khabba, S. Er-Raki, G. Dedieu, A. G. Chehbouni, and A. Olioso, "Monitoring of irrigated wheat in a semi-arid climate using crop modelling and remote sensing data: Impact of satellite revisit time frequency," Int. J. Remote Sens., vol. 27, no. 5/6, pp. 1093-1117, 2006. 